\title{
Nominating Committee Prepares Slate of Candidates for Upcoming Elections
}

\author{
Woody White * \\ Oak Ridge National Laboratory
}

The MRS Nominating Committee is in the process of preparing a slate of candidates for several positions to be submitted to the MRS membership in the upcoming elections. Positions that must be filled for 1986 by the elections include those of 1st Vice President, 2nd Vice President, and five positions on the MRS Council. These elections will determine the leadership of MRS for 1986 and beyond.

\section{Balanced Representation Sought for Officers and Councillors}

The objective of the Nominating Committee is to submit to the membership candidates who would provide strong, creative leadership and oversight to the Materials Research Society and who meet a number of criteria. An important criterion is that the candidates represent a wide range of scientific backgrounds, since one of the main objectives of MRS is the promotion of interdisciplinary research. The 1985 MRS Officers represent scientific backgrounds in physics, chemistry, and geology, and members of the MRS Council have a similar wide-range of scientific interests. Another im portant objective is that candidates represent academic, government, and industrial laboratories, since MRS membership is divided roughly equally along these lines.

Individuals who hold the positions of 1st Vice President and 2nd Vice President are expected to provide leadership to the Society on a daily (even minute- by-minute) basis and individuals who seek these positions must be prepared to make a substantial commitment of their personal time to the Society. These positions are responsible for overseeing most of the MRS Committee activities, and candidates for the Vice Presidential positions must have substantial previous experience with MRS and understand its operation. The individual elected to the position of 1st Vice President is also the PresidentElect, and will serve as President for the following year as provided for in the MRS Constitution.

The Council of MRS is the governing body and the ultimate authority of the Society. The Council is composed of the Officers of the Society and 15 elected Council members. Individual Council members are elected for threeyear terms, and each year five positions on the Council are determined by the elections. Candidates for these positions must be capable of providing careful and thoughtful leadership to the Society. The Council meets twice a year as a body and is responsible for determining all of the major policies and directions for MRS. Candidates for positions of the Council must be capable of assuming these responsibilities. Ideally, the Council should consist of a mixture of individuals who have substantial previous experience with MRS, and some senior individuals with broad vision and experience but limited previous involvement with the Society. These senior "outside" indi-

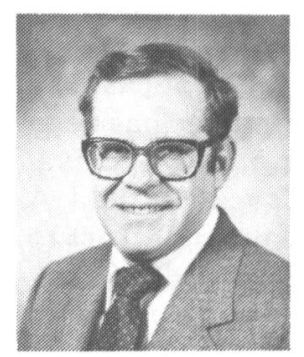

Woody White

viduals are expected to provide an objective as sessment of the MRS mode of operation, while those with MRS experience are expected to keep the Council constantly aware of the scope and purpose of MRS activities.

\section{Nominations Under Consideration}

After the Nominating Committee prepares the slate of candidates, it is submitted to the MRS Council for approval and then submitted to the MRS membership for the vote which will determine the Officers and Council members for the following year. Members can expect to receive their ballots for selection of 1985 Officers and Council by August 1.

MRS is in an extremely rapid growth stage and the prestige and visibility of the Society have increased tremendously in the last two years. The upcoming elections are critically important because the individuals who are selected will be responsible for maintaining and accelerating the momentum which has been established. All members of MRS are encouraged to participate in the election process. This is your Society, and its leaders should be responsive to your needs.

*Woody White is Past President of MRS and chairperson of the Nominating Committee.

\section{Publications Committee (continued from previous page)}

Fradin, Argonne National Laboratory; $\mathrm{H}$. C. Gatos, Massachusetts Institute of Technology; H. Herman, State University of New York-Stony Brook; W. C. Herring, Stanford University; Sir P. Hirsch, University of Oxford; R. Hodgson, IBM, T. J. Watson Research Center; K. A. Jackson, A T\& T Bell Laboratories; Q. Johnson, Lawrence Livermore National Laboratory; E. N. Kaufmann, Lawrence Livermore National Laboratory; R. K. MacCrone, Rensselaer Polytechnic Institute, T. B. Massalski, Naval Postgraduate School, G. L. McVay,
Battelle, Northwest; J. Narayan, Microelectronics Center of North Carolina; C. J. Northup, Sandia National Laboratory; G. A. Oare, MRS Headquarters; R. Osgood, Columbia University; J. M. Phillips, AT\&T Bell Laboratories; S. T. Picraux, Sandia National Laboratory; G. Pike, Sandia National Laboratory; P. Pronko, Universal Energy Systems; J. M. Poate, AT\&T Bell Laboratories, R. Roy, Pennsylvania State University; R. Schwoebel, Sandia National Laboratory; T. W. Sigmon, Stanford University; K. C. Taylor, GM Research Labora- tories; L. Testardi, National Bureau of St andards; K. N. Tu, IBM. T. J. Watson Research Laboratory; A. R. von Hippel, Weston, MA; F. F. Y. Wang, State University of New York-Stony Brook; C. W. White, Oak Ridge National Laboratory; F. W. Young, Oak Ridge National Laboratory.

Many other individuals contributed to this survey, but due to space limitations, they cannot all be listed here.

*Dave Campbell serves as chairperson of the fournal Subcommitter which conducted the survey described in this report. 